\title{
Psychological types and self-assessed leadership skills of clergy in the Church of England
}

\author{
Laura Watt and David Voas
}

\begin{abstract}
Laura Watt: Cathie Marsh Institute for Social Research, University of Manchester, Oxford Road, Manchester M13 9PL

David Voas: Institute for Social and Economic Research, University of Essex, Wivenhoe Park, Colchester CO4 3SQ

voas@essex.ac.uk
\end{abstract}

\begin{abstract}
The study uses data from an online survey of parish churches carried out in 2013 for the Church of England. It obtained a sample of 1,480 clergy, mainly stipendiary. As expected from previous studies, there were relatively high frequencies of psychological types marked by introversion, intuition, feeling and judging. Gender differences were small. Clergy also provided self-assessments of their abilities in a number of areas related to parish ministry. Personality has substantial effects on these leadership strengths, although the types that have positive associations are often not those most commonly found among Anglican clergy. A single scale can be created for most of the qualities (including managing, motivating, innovating, etc.), but empathising and connecting do not belong on the same dimension. If clergy are to be deployed effectively, it may be desirable to distinguish between positions calling for good general leaders and those where the emphasis is on pastoral work.
\end{abstract}




\section{Psychological types and self-assessed leadership skills of clergy in the Church of England}

\section{Introduction}

The relationship between personality and leadership has been discussed by psychologists, sociologists, economists, and others. These discussions address various questions such as: are people of some personality types more likely to emerge as leaders than others? Can we predict the kind of leader a person will become from his or her personality? Do certain traits make for better leaders?

Studies that have addressed the last of these questions in particular have tended to focus on corporate leadership and to measure personality via the "Big Five" dimensions: extraversion, agreeableness, emotional stability (versus neuroticism), conscientiousness, and openness to experience (Digman, 1990). Many of these studies show that this five factor model of personality can be used to predict leadership effectiveness. There are, however, inconsistencies between them in terms of which personality traits appear to have an effect and the size of those effects. For example, McRae at al. (1996) found extraversion, agreeableness, emotional stability and conscientiousness to be most related to leadership effectiveness, with openness to experience much less so. Meanwhile, in their meta-analysis of existing empirical work, Judge et al. (2002) found that agreeableness had no effect on leadership effectiveness. Different again are the results of Silverthorne (2001) who, in his cross-national study of leadership and personality, found that all of the big five personality traits had a positive effect upon leadership (at least in the US).

The most consistent finding in studies of leadership and personality seems to be the association between extraversion and leadership effectiveness: extraverts tend to make better leaders than introverts (Colbert et al., 2012; Polyhart et al., 2001). Colbert et al. (2012) claim that many studies of personality and leadership actually underestimate the association between these two constructs because of the ways in which they are measured. They argue that while most of these studies rely upon self-reported measures of personality, 
in order to see the real effect personality has upon leadership, observer-reported measures should be used instead. Oh et al. (2011) agree with this view, reporting stronger associations between leadership and extraversion when the latter is rated by an observer rather than the subject.

While there is some evidence that such individual differences can be used to predict leadership effectiveness, authors such as Anderson (2006) strongly criticise this emphasis on personality. They argue instead for the instrumental approach, which is more concerned with what leaders do than who they are as a means of distinguishing between the successful and unsuccessful. Anderson (2006) claims that while a leader's personality might be associated with his or her success, it will only be so to the extent that personality affects his or her behaviour. In his view it is the action of the leader that makes the difference. This action might be the result of personality but it might also result from situational factors. Farkas and Wetlaufer (1996) found, for example, that the corporate environment was a key influence on the behaviour of company leaders, regardless of their personality. Anderson (2006) therefore questions the relationship between personality and leadership, suggesting that traits alone are not enough to explain leadership effectiveness and are at best preconditions that might encourage certain behaviours.

This debate raises interesting questions regarding leadership and the age-old question of nature versus nurture: are leaders born, or are they made? We enter this debate by investigating the association between personality and leadership among clergy in the Church of England. In particular we are interested in whether people of certain psychological types appear to be better suited than others to ordained leadership. The ways in which personality is associated with leadership in a corporate setting may not apply to the religious sphere. In their study of personality and job performance, Barrick and Mount (1991) found that different personality traits can have different effects in different occupational settings.

Scholarly interest has been growing in the distribution of clergy by psychological type and the implications of that distribution (see for example Francis et al., 2007; Francis \& Village, 2012). In 2013, measures of personality were included as part of the Church of England's 
survey for the Church Growth Research Programme, which was designed to explore potential causes of church growth and decline. Results from the study suggest that church growth is significantly associated with the personality of the ordained minister, and specifically with extraversion, intuition and emotional stability (Voas \& Watt, 2014).

Growth of a congregation could be used as a measure of leadership effectiveness for clergy, though of course it would be a limited one. Increasing the size of the flock is just one aspect of church leadership; clergy are also expected to tend to the existing flock by providing religious instruction, pastoral care and administering the sacrament as well as managing lay leaders, organising finances and liaising with members of the wider community - to mention just a few of their functions. Each of these varied roles could be associated with personality in different ways. In the present study we look at how psychological type might influence leadership strengths more broadly among the clergy. Alongside the issue of personality, we also explore how age and sex affect this relationship.

\section{Data}

\section{Sample}

The data used in this study come from a large online survey administered between April and July 2013 as part of the Church of England's Church Growth Research Programme. The survey was designed to identify factors related to numerical change in church attendance. Invitations were sent by e-mail to ordained ministers - most with incumbent status - in a large sample of parishes. More detail regarding the sample and overall study can be found in Voas and Watt (2014).

The survey consisted of two main parts. The first was principally concerned with profiling the church in terms of size, worship style, activities and so on. Responses were received from 1,703 churches. The second part was to be completed by the ordained minister most closely associated with the church. Here the questions included age, date of ordination, type of post, theological orientation and other characteristics. This section also featured the batteries on personality and leadership that are used in the work described below. 
The clergy portion of the questionnaire was completed for the large majority of churches in the achieved sample, with the result that we have full data on nearly 1,500 Anglican clergymen and women. All respondents are in parish ministry; $95 \%$ are stipendiary and $90 \%$ full-time. Incumbents are over-represented in the sample and curates, self-supporting ministers and ordained local ministers are under-represented.

\section{Measures}

\section{Psychological type}

By kind permission of Leslie Francis, the survey included the battery of items used for the Francis Personality Type Scales (FPTS). Like the familiar Myers-Briggs system, these scales represent an attempt to operationalise psychological type theory rooted in the pioneering work of Carl Jung. The strength of the FPTS is that it was designed for use in large scale surveys rather than in individual consultation or clinical contexts. There are four dimensions, identified by the letter in upper case: Extraversion - Introversion, Sensing - iNtuition, Thinking - Feeling, Judging - Perceiving. An additional dimension in the FPTS was called neuroticism by Eysenck (and is also in the Five Factor model of personality), though it might more helpfully be referred to as emotional stability.

E and I distinguish between two orientations: towards the outside world in the case of Extraversion, or the inner world in the case of Introversion. Extraverts thrive off company, feeling energised through contact with others, preferring to socialise than to be alone. Introverts, on the other hand, tend to feel drained by social events and too much contact with other people; they gain their energy from being alone, working out problems in solitude rather than talking them through.

$\mathrm{S}$ and $\mathrm{N}$ distinguish between two ways of perceiving or processing information, either through one's senses or intuition. Sensing types look to, and prioritise, the specific and concrete details of a situation, concerned with the finer practical points of how something might be accomplished. Intuitive types are less concerned with such detail, preferring to look at the general picture of what they observe and what they would like to accomplish rather than focusing on the practicalities of how it might happen. Francis and Village (2012) note that people of this type can appear to be 'up in the air' and 'idealistic dreamers'. 
T and $\mathrm{F}$ distinguish between ways of making judgements. Thinking types make judgements, or decisions, based on knowledge, facts about the situation and values they hold and adhere to. As such, they tend to remain objective even when tough decisions need to be made. Conversely, feeling types are more subjective in their decision making, prioritising the desire to make people happy or keeping the peace above adherence to external criteria and rules.

$\mathrm{J}$ and P concern a person's attitude towards the outside world. Judging types have an organised and structured approach to doing things. They enjoy routine and schedules, finding it difficult to be spontaneous or to deal with unexpected situations or change in general. Perceiving types have a much less fixed approach to life, enjoy being spontaneous and welcome change. They tend to be more impulsive than judging types and so are less likely to stick to previously made plans and decisions.

A fifth dimension in Francis' instrument distinguishes between emotional stability and instability. Those inclined towards the latter tend to be more susceptible to worry and stress than the emotionally stable, who are more likely to remain calm and rational in any situation and are better able to cope with problems that arise.

Each of these five dimensions of personality is measured on an 11-point scale. These measures can be dichotomised, as has been done for some analyses reported here. In general, however, we treat the dimensions as continuous variables. We label each dimension using one or the other pole (e.g. extraversion rather than introversion) as a matter of convenience. Choosing the other pole would give the same results with the opposite sign.

On the basis of the four main dimensions (excluding emotional stability), every respondent can be assigned one of 16 possible psychological types, combining a dominant orientation (extraversion or introversion), a dominant perceiving process (sensing or intuition), a dominant judging process (thinking or feeling), and a dominant attitude towards the outside word (judging or perceiving). The result is described by a four letter combination such as 
ENTJ or ISFP. This categorical typology is also used in this study.

\section{Leadership measure}

The principal aim of the survey was to help identify factors associated with church growth or decline, which might include characteristics of the ordained minister. A great deal of work in this area has been done by NCLS Research in Australia, and we took particular inspiration from their analysis of leadership strengths. Their investigations follow the psychometric tradition: respondents complete a large battery of questions and are scored on the basis of their answers. Time and space constraints meant that it was not possible to adopt the same approach in our survey, and so we asked clergy to assess their own strengths in eight areas. The question was as follows:

What do you see as your strengths? Some of your qualities will be more or less developed, either in relation to each other or relative to the characteristics of others. How would you rate yourself on each of the following attributes? [The questionnaire presented a 7-point Likert scale with the endpoints marked 'no special talent' and 'better than most people'.]

- Empathising: sensing what other people are feeling; listening and counselling

- Speaking: being confident when giving a sermon or addressing a formal meeting

- Innovating: regularly coming up with new ways of doing things

- Connecting: spending time with people in the community and listening to their views

- Managing: creating good systems and providing clear expectations to lay leaders

- Envisioning: having a clear vision for the future and being focused on achieving it

- Persisting: finishing what you start, despite obstacles in the way

○ Motivating: generating enthusiasm and inspiring people to action

While we believe that these eight qualities encompass important aspects of clerical leadership, we recognise that there may be relevant strengths that are not measured here. A larger concern is that the self-perceptions underlying these assessments may be inaccurate. Inflated scores would not be too serious if the bias is either universal or randomly occurring, but it seems possible that the degree of over-estimation may be influenced by personality. For example, one might expect that extraverts rate themselves more highly than similarly talented introverts, or that neuroticism leads to lower selfconfidence. 
In fact, our results do show positive associations between both extraversion and emotional stability and the various leadership strengths. While it is highly plausible that people of these psychological types are indeed more able leaders, they might also be more prone to high self-regard. Identifying the extent of causality in each direction is far from straightforward.

\section{Results}

\section{Psychological type: descriptive statistics}

The findings on psychological type from the current study are broadly consistent with previous research on Anglican clergy, both male and female (Francis et al., 2007; Francis et al., 2010; Francis et al., 2011). As shown in Table 1, introversion, intuition, feeling and judging are the dominant types. The gender differences are relatively small. Francis et al. (2007) report that male and female Anglican clergy are similarly likely to belong to types I, N, and J, but that a considerably higher proportion of ordained women should be classed as Feeling (as is the case for women generally). The same contrast can be observed in comparing the findings of Francis et al. (2010) and Francis et al. (2011) for male and female Anglican clergy respectively. We found a much smaller gap that is not statistically significant.

$<$ Table $1>$

Francis and colleagues report that upwards of $60 \%$ of Church of England clergy have intuition rather than sensing as their perceiving function, and we find slightly smaller majorities of this type for both men and women. On the other dimensions our figures for men are close to those in either Francis et al. (2007) or Francis et al. (2010). The current study shows a lower prevalence of Feeling and also a higher prevalence of Judging among female Anglican clergy than reported in earlier work.

The differences between clergy and the general population in psychological type are much as have already been described in the literature. Anglican clergymen are considerably more likely than other men to be classed as N, F and J, although their level of introversion is not distinctive. For women, $\mathrm{N}$ and $\mathrm{J}$ are also high for Anglican clergy, but otherwise the contrast 
comes in higher levels of Introversion, with F being similar to the population norm. To put the matter another way, a majority of Anglican clergymen have what might seem to be feminine levels of feeling and judging, while ordained women are somewhat more introverted than the gender norm. The preference for intuition is relatively high among both male and female clergy in the Church of England.

Despite the preponderance of intuition, we found ISFJ to be the most prevalent psychological type among both male and female Anglican clergy (12.8\% and $18.9 \%$ respectively). INFJ, which combines the types that taken individually are observed most frequently, characterises $10.9 \%$ of men and $10.4 \%$ of women in our sample. Other common types are INTJ (10.4\% and 10.7\% for men and women respectively) and ISTJ (10.4\% of ordained men). The last three columns of Table 5 show the full list for all clergy (men and women combined), as compared to the general UK population.

\section{Leadership strengths: descriptive statistics}

Table 2 lists the mean scores for each leadership quality. Anglican clergy appear to have a relatively high degree of confidence in their own abilities: the means range from 4.27 to 5.77 on a 7-point scale, and for all factors with the exception of 'managing' the median score is at least 5.

$<$ Table $2>$

Respondents were most likely to be positive about their 'speaking' ability, i.e. feeling confident when giving a sermon or addressing a formal meeting. Speaking, empathising and motivating are all near the top of the list with mean ratings over five. Respondents were least confident about 'managing', defined as creating good systems and providing clear expectations to lay leaders.

\section{Bivariate associations with leadership strengths}

Age is not strongly correlated with any of the self-reported leadership strengths, but in three instances there are statistically significant associations. Younger ordained ministers 
are more likely to say that they are good at innovating and envisioning, while older clergy score highly in persisting ('finishing what you start, despite obstacles in the way').

These results are consistent with stereotypes about the young and old. Youth is associated with a desire to change; innovating is about creating new ways of doing things, while envisioning involves having a vision for the future. Younger leaders may be relatively forward thinking. In contrast, older leaders may be more reliable and effective at following through on a plan, though persistence may also translate into inflexibility (Voas \& Watt, 2014).

There are some significant differences between the mean scores of male and female clergy. Ordained women appear to be stronger at empathising (5.69 compared to 5.15 for men), connecting (4.72 versus 4.43 ) and motivating (5.43 versus 5.06). Male clergy give themselves relatively high marks for speaking ( 5.85 compared to 5.49 for women). It is no surprise that women have the edge with empathy and connecting (defined as 'spending time with people in the community and listening to their views'), nor that men feel especially confident in public performance. The result for motivating is more intriguing, not least because this strength is one that emerges as particularly important for church growth, although there is no association between clergy gender and growth (Voas \& Watt, 2014).

Table 3 shows the correlations between the five personality traits (extraversion, intuition, thinking, judging and emotional stability) and the eight leadership qualities. The main associations with each strength are consistent with expectations: empathising goes hand in hand with high scores on feeling; connecting and motivating are linked to extraversion; innovating and envisioning are promoted by intuition; and both managing and persisting relate to judging.

$<$ Table $3>$

Note that the psychological types that are found most frequently among Anglican clergy are not always those most closely correlated to leadership strengths. In particular, extraversion has a significantly positive association with most of the qualities, but the majority of 
ordained ministers are introverts. Likewise clergy tend to be strong on feeling, which is negatively correlated with managing, envisioning, persisting, speaking and innovating. The position with judging is somewhat better, though this type does not rate highly on innovating. The most promising observation is that a majority of these ordained ministers are of the intuitive type, which is positively correlated with most of the strengths. While "there is a danger that the wider population [three quarters of whom prefer sensing to intuition] may view clergy as having little to say to "the real world'" (Francis et al., 2007, p. 281), it is at least possible that these individuals are more effective leaders than others.

\section{Multivariate versus bivariate analyses}

To go beyond the bivariate correlations described above, we used linear regression to investigate the relative effect of age, sex and each personality trait on the self-assessed leadership ratings. Table 4 shows the results, where each of the eight leadership strengths was taken in turn as the dependent variable. The rows list the independent variables (age, sex and the five psychological types), and the values in the table are the standardised coefficients for each. We are thus able to assess the relative effects of each variable on the different measures of leadership.

$<$ Table $4>$

The results of the multivariate analysis are largely in line with those reviewed above from the bivariate analyses, suggesting that for the most part the factors have independent effects. The differences that are observed are related to intuition and judging, which are inversely related: in this dataset the correlation between these two types is -0.425 . Considering both variables simultaneously using regression techniques is particularly helpful in distinguishing their effects.

Innovating, for example, shows a substantial negative correlation with judging. Intuition is even more strongly associated with innovating, however, and judging ceases to have any effect when controlling for that characteristic. In other words the correlation arises only because of the connection between intuition and perceiving; the first type is strongly 
related to innovating but the second is not. The same phenomenon can be seen in reverse with persisting, where the strong association with judging produces a 'spurious' negative correlation with intuition.

There are also shifts in the strength and even the direction of the associations with respect to managing, envisioning and motivating. Judging has a strong influence on managing, which shows a small negative correlation with intuition. In a multivariate analysis, however, it turns out that the influence of intuition is actually positive. The story with envisioning and motivating is essentially the same in reverse: the positive effect of judging is suppressed in the bivariate correlation because intuition is so important.

Finally, connecting is unusual in that the small but significant bivariate associations with intuition and judging do not survive in multivariate analysis, where sex has a more important role.

\section{Findings from the multivariate analysis}

As one might expect, empathising is most strongly associated with feeling. While thinking types try to remain objective in judging situations, making decisions based on external values, feeling types tend to place greater importance on ensuring the peace and happiness of those with whom they interact. Such people would seem more naturally empathetic. Interestingly, empathising is the only leadership quality that is negatively associated with emotional stability. The effect is small yet significant and points to the fact that sensitivity can be a positive attribute.

Speaking is not strongly associated with any personality trait though it is moderately, and positively, linked to extraversion, intuition, thinking and emotional stability. These traits seem plausibly related to having confidence when speaking to groups of people.

The strongest relationship in the entire table is between intuition and innovating. People who lean towards the intuition (rather than sensing) end of the perceiving dimension are inclined to look at the bigger picture rather than concrete details when processing information. They are more interested in an overall vision of what might be accomplished 
than in the practicalities of how that vision will come to pass. The intuitive way of perceiving the world therefore seems to lend itself to innovation or coming up with new ways of doing things. A tendency to overlook the details of how something might work seems potentially valuable, at least in the first instance, when creating new systems. For similar reasons, envisioning is also strongly linked to intuition.

Connecting is most strongly associated with extraversion. The fact that extraverts thrive off interacting with other people would suggest that they are more comfortable, and therefore better at, connecting, defined here as spending time with people in the community and listening to their views. Motivating is also strongly associated with extraversion. Again, an outgoing personality seems suited to this leadership quality; someone who gains energy from being with others is arguably better at motivating others to action than someone more reserved.

Finally, both managing and persisting are strongly linked to judging. Judgers, unlike perceivers, like to be organised and structured rather than impulsive and spontaneous, qualities that help to support these strengths.

Overall, the results suggest that extraversion and intuition are most consistently associated with the leadership qualities being considered here. The effects of emotional stability are somewhat more modest, but with a single exception (empathising) it is positively and significantly associated with the various leadership strengths. As noted earlier, we need to cautious about interpreting some of these findings. Extraverts and introverts, and the emotionally stable and unstable, might have different perceptions of their own abilities.

\section{A scale measure of leadership}

Both factor analysis and classical reliability analysis indicate that a good scale can be formed by combining six out of the eight leadership strengths (all except empathising and connecting). The value of Cronbach's alpha is 0.73 . The multi-item scale is created by calculating the mean of the six original leadership measures. 
By creating a single measure of leadership that combines most of these qualities, we can produce a model to measure the relative effect of each independent variable on leadership more generally. The last column in Table 4 shows the results of a linear regression treating this multi-item leadership scale as the dependent variable. Sex has no significant effect on overall leadership ratings. Being female is positively associated with empathising and connecting, both of which have been excluded from the scale. The only other significant effects are counter-balancing: men rate themselves as better at speaking while women give themselves higher marks for motivating. The effect of age is small, but older clergy do tend to have higher leadership scores. Each of the personality traits is found to have a significant effect on this combined measure of leadership; starting from the most important, the positive influences come from intuition, extraversion, judging, emotional stability and finally thinking (as opposed to feeling).

\section{Psychological types and leadership ratings}

The results in Table 4 for the scale measure imply that ENTJs are likely to score most highly in self-assessed leadership strengths, which is indeed the case. Table 5 shows the full set of 16 psychological types in descending order of leadership scale scores.

$<$ Table $5>$

There are striking differences between the EN (extroversion + intuition) and IS (introversion + sensing) psychological types. Three of the top four positions in the table are occupied by the former; the bottom three places are taken by the latter. These results go some way to explaining the finding that IS clergy are three times as likely to preside over decline as substantial growth, whereas EN clergy are twice as likely to report substantial growth as decline (Voas \& Watt, 2014). Personality matters to church growth in part because some key abilities come more or less naturally to different types of people, not least motivating (generating enthusiasm and inspiring people to action) and envisioning (having a clear vision for the future and being focused on achieving it). 
Of course it should be remembered that Table 5 shows mean values, and there will be considerable dispersion of scores for people of any given type. Moreover some introvert types rank higher than some extravert types (e.g. INTJ versus ESTP), just as some sensing types score better than some intuitive types (e.g. ESTJ versus ENFP). There will be considerable overlap in the strengths of people belonging to different types, whether we are considering one, two or all four dimensions combined.

In addition, one should bear in mind that the qualities of empathising and connecting are not included in this leadership scale. Those strengths are associated with different psychological types. The highest rating for empathising goes to INFP, which only barely escapes the lowest quartile in Table 5. The Church of England would not be well served by a unidimensional approach to the selection of ordinands.

Encouragingly for the Church, the psychological types with higher mean scores on the leadership scale tend to be over-represented among clergy, relative to the general population. (Whether they should be much more so is another question.) It is clear from comparing the top and bottom halves of the last column in Table 5 that ordained ministers are already selected - or self-selected - to have some of the qualities needed for the role. The best candidate for the psychological type that might be the parochial all rounder - both a good leader and a good listener - is ENFJ: it takes second place in the mean scores on both the leadership scale and the empathising dimension. There are more than three times as many Anglican clergy of this type as one would find in the UK population. Whether by accident or design, at least some people seem to be finding their vocation.

\section{Conclusion}

As previous studies have shown, Church of England clergy have a distinctive psychological type profile. They are more likely than other people in the UK to be characterised by introversion, intuition, feeling and judging. We do not find large differences between the ordained men and women in our sample in personality. 
Anglican clergy tend to see themselves as having better than average abilities in a number of areas related to parish ministry. They have most confidence in speaking and empathising, and least in managing and connecting. Although the gender differences in self-assessed leadership strengths are not great, they do emerge with particular qualities. Consistent with stereotypes, men generate the highest marks for public speaking, while women are strong in one-to-one empathising. Perhaps less expectedly, women also score more highly on both motivating and managing.

Personality has substantial effects on these leadership strengths. Unfortunately the types that have positive associations are often not those most commonly found among Anglican clergy. In particular, there is arguably a shortage of ordained ministers characterised by extraversion and thinking (rather than introversion and feeling). That said, the considerable bias towards intuition and judging (as opposed to sensing and perceiving) may benefit the Church of England.

Most of the qualities considered here - managing, motivating, innovating and so on - can be regarded as manifestations of an underlying aptitude. Only empathising is clearly a separate dimension; the primary scale is slightly improved by leaving out connecting, but the difference is marginal. The implications for recruitment and deployment of clergy are interesting. On the one hand, many of the required strengths do go together, and it should be possible to identify which individuals seem well or less well suited to the demands of ordained ministry. On the other hand, a focus on that single dimension would neglect empathising, which must be a key attribute for some roles. It may be necessary to distinguish the good general leaders - strong on extraversion, thinking, judging and emotional stability - from the good pastoral workers, whose effectiveness is promoted by feeling and is not inconsistent with a degree of emotional instability. Whether certain types of people are genuinely strong in both areas is a topic for further study.

While personality matters considerably to leadership - we have accounted for a quarter of the variance on our scale measure - it is just as clearly not the whole story. Some people may be born to lead, but others achieve leadership, and many clergy have leadership thrust upon them. Parish ministry makes broad demands. The environment may make the minister, 
and some qualities might be nurtured beyond nature's initial endowment. Nevertheless, the well-being of both clergy and the churches they serve would be promoted by fitting the right pegs in the right holes.

\section{References}

Andersen, J.A. (2006). Leadership, personality and effectiveness. The Journal of SocioEconomics, 35, 1078-1091.

Barrick, M.R., \& Mount, M.K. (1991). The Big Five personality dimensions and job performance: A meta-analysis. Personnel Psychology, 44 (1), 1-26.

Colbert, A.E., Judge, T.A., Choi, D., \& Wang, G. (2012). Assessing the trait theory of leadership using self and observer ratings of personality: The mediating role of contributions to group success. The Leadership Quarterly, 23, 670-685.

Digman, J. (1990). Personality structure: Emergence of the five-factor model. Annual Review of Psychology, 41, 417-440.

Farkas, C.M., \& Wetlaufer, S. (1996). The ways chief executive officers lead. Harvard Business Review, 74(3), 110-122.

Francis, L.J., Craig, C.L., Whinney, M., Tilley, D., \& Slater, P. (2007). Psychological typology of Anglican clergy in England: Diversity, strengths, and weaknesses in ministry. International Journal of Practical Theology, 11, 266-284.

Francis, L.J., Robbins, M., Duncan, B., \& Whinney, M. (2010). Confirming the psychological type profile of Anglican clergymen in England: A ministry for intuitives. In B. Ruelas \& V. Brisero (Eds.), Psychology of intuition (pp. 211-219). New York, NY: Nova Science.

Francis, L.J., Robbins, M., \& Whinney, M. (2011). Women priests in the Church of England: Psychological type profile. Religions, 2, 389-397.

Francis, L.J., \& Village, A. (2012). The psychological temperament of Anglican clergy in Ordained Local Ministry (OLM): The conserving, serving pastor? Journal of Empirical Theology, 25, 57-76.

Judge, T.A., Bono, J.E., Ilies, R., \& Gerhardt, M. (2002). Personality and leadership: A qualitative and quantitative review. Journal of Applied Psychology, 87, 765-780.

Kendall, E. (1998). Myers-Briggs Type Indicator: Step 1 Manual Supplement. Palo Alto, CA: Consulting Psychologists Press. 
McCrae R.R., Costa P.T., Jr., \& Yik, M.S.M. (1996). Universal aspects of Chinese personality structure. In M.H. Bond (ed.), The handbook of Chinese psychology (pp. 189-207). Hong Kong: Oxford University Press.

Oh, I.S., Wang, G., \& Mount, M.K. (2011). Validity of observer ratings of the five-factor model of personality: A meta-analysis. Journal of Applied Psychology, 96, 762-773.

OPP (2011). MBTI Step 1 instrument: European Data Supplement. Oxford: OPP Ltd.

Ployhart, R.E., Lim, B.C., \& Chan, K.Y. (2001). Exploring relations between typical and maximum performance ratings and the five factor model of personality. Personal Psychology, 54 (4), 809-843.

Silverthorne, C. (2001). Leadership effectiveness and personality: A cross cultural evaluation. Personality and Individual Differences, 30, 303-309.

Voas, D., \&Watt, L. (2014). Numerical change in church attendance: National, local and individual factors. Report commissioned by the Church of England.

http://www.churchgrowthresearch.org.uk/progress_findings_reports 
Table 1: Psychological type of male and female Anglican clergy (\%)

\begin{tabular}{|c|c|c|c|c|}
\hline \multirow[b]{2}{*}{ Type } & \multicolumn{4}{|c|}{ MEN } \\
\hline & UK & Francis et al. 2007 & $\begin{array}{c}\text { Francis et al. } 2010 \\
\text { / Francis et al. } \\
2011\end{array}$ & $\begin{array}{c}\text { Church Growth } \\
\text { Research }\end{array}$ \\
\hline I & 53 & 57 & 64 & 55 \\
\hline $\mathrm{N}$ & 27 & 62 & 67 & 55 \\
\hline $\mathrm{F}$ & 35 & 54 & 56 & 59 \\
\hline$J$ & 55 & 68 & 73 & 75 \\
\hline \multirow[t]{2}{*}{ Sample size } & 748 & 626 & 622 & 1,172 \\
\hline & \multicolumn{4}{|c|}{ WOMEN } \\
\hline I & 43 & 54 & 63 & 59 \\
\hline $\mathrm{N}$ & 21 & 65 & 60 & 56 \\
\hline $\mathrm{F}$ & 70 & 74 & 76 & 63 \\
\hline$J$ & 62 & 65 & 55 & 76 \\
\hline Sample size & 865 & 247 & 83 & 308 \\
\hline
\end{tabular}

Source : UK population norms are provided by Kendall (1998). Figures in the penultimate column are taken from Francis et al. (2010) for men and Francis et al. (2011) for women.

Table 2: Self-reported leadership scores among Church of England clergy

\begin{tabular}{lcccc}
\hline & Mean & $\begin{array}{c}\text { Std. } \\
\text { Dev. }\end{array}$ & Men & Women \\
\hline Speaking & 5.77 & 1.08 & 5.85 & 5.49 \\
Empathising & 5.26 & 1.30 & 5.15 & 5.69 \\
Motivating & 5.14 & 1.21 & 5.06 & 5.43 \\
Persisting & 4.86 & 1.43 & 4.86 & 4.86 \\
Envisioning & 4.85 & 1.35 & 4.86 & 4.82 \\
Innovating & 4.73 & 1.45 & 4.73 & 4.76 \\
Connecting & 4.49 & 1.35 & 4.43 & 4.72 \\
Managing & 4.27 & 1.43 & 4.25 & 4.36 \\
& & & & \\
Sample size & 1,480 & & 1,172 & 308 \\
\hline
\end{tabular}

Note: Scale from 1 ('no special talent') to 7 ('better than most people') 
Table 3: Correlations between leadership strengths and psychological types

\begin{tabular}{|c|c|c|c|c|c|c|c|c|}
\hline & Empathising & Speaking & Innovating & Connecting & Managing & Envisioning & Persisting & Motivating \\
\hline Extraversion & 0.05 & $0.16^{* *}$ & $0.26 * *$ & $0.30 * *$ & $0.11^{* *}$ & $0.18^{* *}$ & 0.00 & $0.36 * *$ \\
\hline Intuition & $0.11^{* *}$ & $0.18^{* *}$ & $0.45^{* *}$ & $0.09 * *$ & $-0.05^{*}$ & $0.29 * *$ & $-0.13^{* *}$ & $0.22^{* *}$ \\
\hline Feeling & $0.27^{* *}$ & $-0.14^{* *}$ & $-0.13^{* *}$ & $0.15^{* *}$ & $-0.20 * *$ & $-0.19 * *$ & $-0.17^{* *}$ & 0.04 \\
\hline Judging & $-0.09 * *$ & $-0.06^{*}$ & $-0.20 * *$ & $-0.13^{* *}$ & $0.35^{* *}$ & $0.05^{*}$ & $0.29 * *$ & $-0.09 * *$ \\
\hline Emotional Stability & $-0.09 * *$ & $0.10^{* *}$ & $0.07^{* *}$ & $0.08 * *$ & $0.19 * *$ & $0.14^{* *}$ & $0.11^{* *}$ & $0.17^{* *}$ \\
\hline
\end{tabular}

$* \mathrm{p}<0.05 * * \mathrm{p}<0.01$

Table 4: Standardised coefficients from linear regression models showing effects of age, sex and personality on leadership strengths

\begin{tabular}{|c|c|c|c|c|c|c|c|c|c|}
\hline & Empathising & Speaking & Innovating & Connecting & Managing & Envisioning & Persisting & Motivating & Scale \\
\hline Age & 0.04 & -0.00 & -0.02 & 0.04 & 0.03 & -0.01 & $0.15^{* *}$ & 0.03 & $0.05^{*}$ \\
\hline Female & $0.15^{* *}$ & $-0.13 * *$ & 0.02 & $0.10 * *$ & $0.05^{*}$ & -0.00 & 0.01 & $0.14^{* *}$ & 0.03 \\
\hline Extraversion & 0.03 & $0.15^{* *}$ & $0.21 * *$ & $0.28 * *$ & $0.19 * *$ & $0.18 * *$ & $0.07 * *$ & $0.33 * *$ & $0.28 * *$ \\
\hline Intuition & $0.10 * *$ & $0.16 * *$ & $0.42 * *$ & 0.05 & $0.11^{* *}$ & $0.36 * *$ & -0.01 & $0.21 * *$ & $0.32 * *$ \\
\hline Feeling & $0.27^{* *}$ & $-0.15^{* *}$ & $-0.15^{* *}$ & $0.12 * *$ & $-0.12 * *$ & $-0.16 * *$ & $-0.11 * *$ & 0.02 & $-0.17 * *$ \\
\hline Judging & 0.02 & 0.01 & -0.01 & -0.01 & $0.41 * *$ & $0.22 * *$ & $0.29 * *$ & $0.08 * *$ & $0.26 * *$ \\
\hline Emotional Stability & $-0.05^{*}$ & $0.09 * *$ & $0.07 * *$ & $0.06 *$ & $0.19 * *$ & $0.15^{* *}$ & $0.11 * *$ & $0.18 * *$ & $0.20 * *$ \\
\hline Adjusted $\mathrm{R}^{2}$ & 0.11 & 0.10 & 0.27 & 0.12 & 0.22 & 0.20 & 0.14 & 0.20 & 0.25 \\
\hline
\end{tabular}

$* \mathrm{p}<0.05 * * \mathrm{p}<0.01$

Note: As described in the text, the scale is the mean value for speaking, innovating, managing, envisioning, persisting and motivating, i.e. all qualities except empathising and connecting. 
Table 5: Scale measure of leadership strengths by psychological type

\begin{tabular}{lrrrrr}
\hline Psychological type & Mean & $\begin{array}{r}\text { Std. Error of } \\
\text { Mean }\end{array}$ & $\mathrm{N}$ & $\%$ & SSR \\
\hline ENTJ & 5.46 & 0.08 & 91 & 6.3 & 2.14 \\
ENFJ & 5.37 & 0.07 & 128 & 8.8 & 3.21 \\
ESTJ & 5.30 & 0.07 & 89 & 6.2 & 0.59 \\
ENTP & 5.25 & 0.12 & 46 & 3.2 & 1.15 \\
INTJ & 5.20 & 0.07 & 149 & 10.3 & 7.32 \\
INTP & 5.00 & 0.13 & 34 & 2.3 & 0.96 \\
ESFJ & 4.96 & 0.08 & 134 & 9.3 & 0.73 \\
ENFP & 4.94 & 0.07 & 112 & 7.7 & 1.23 \\
ESFP & 4.85 & 0.15 & 31 & 2.1 & 0.25 \\
ISTJ & 4.84 & 0.06 & 144 & 10.0 & 0.73 \\
INFJ & 4.75 & 0.07 & 156 & 10.8 & 6.29 \\
INFP & 4.72 & 0.11 & 72 & 5.0 & 1.56 \\
ESTP & 4.67 & 0.22 & 14 & 1.0 & 0.17 \\
ISFJ & 4.52 & 0.06 & 205 & 14.2 & 1.11 \\
ISFP & 4.12 & 0.14 & 32 & 2.2 & 0.36 \\
ISTP & 4.08 & 0.31 & 10 & 0.7 & 0.11 \\
\hline
\end{tabular}

Note: The self-selection ratio (SSR) is the ratio of the relative frequency of the type in this dataset to that in the general UK population (OPP 2011). 